\title{
Value of Mammary Thermography in Differential Diagnosis
}

\author{
B. E. NATHAN, J. IAN BURN, D. P. MACERLEAN
}

British Medical fournal, 1972, 2, 316-317

\section{Summary}

Thermographic examinations of the breasts were carried out in 359 women, most of whom had mammary symptoms. Of the 195 patients with abnormal thermograms, 27 had cancer of the breast, 53 had benign lesions, and 115 had no confirmed organic disease. The incidence of falsepositive thermograms was $59 \%$. Of the 164 patients with normal thermograms, 116 had no confirmed organic disease, 41 had benign lesions, and 7 had cancer. The incidence of false-negative mammary thermograms was $29 \%$.

We conclude that mammary thermography is of no practical value in the differential diagnosis of symptomatic mammary disease.

\section{Introduction}

The clinical diagnosis of cancer of the female breast at a stage when the patient presents with symptoms is generally correct, but not always. Most surgeons, therefore, prefer to obtain confirmation of malignancy by preliminary biopsy before proceeding to definitive therapy. It is probable that all methods of biopsy cause the dissemination of cells from the primary tumour, with the consequent risk of metastatic disease. For this reason if no other there is justification for careful evaluation of other potential methods of diagnosing cancer of the breast. Mammary thermography has attracted considerable interest in this respect during the past decade (Lloyd Williams et al., 1961; Gershon-Cohen et al., 1965; Draper and Jones, 1969; Furnival et al., 1970), enthusiasm for the method being varied.

We report our own experience of mammary thermography in the differential diagnosis of women with established mammary symptomatology attending the Hammersmith Breast Clinic.

\section{Methods}

A total of 359 patients had thermographic examinations. These women presented at the breast clinic for a variety of reasons (Table I)-346 complained of mammary symptoms and 13 requested examination although they had no symptoms. The mean age of the patients in the series was 37 years, and 274 $(76 \%)$ of them were premenopausal. Thermography was carried out at their first attendance irrespective of the stage of

TABLE I-Reasons for Referral to Breast Clinic in 359 Cases

\begin{tabular}{|c|c|c|c|c|c|c|}
\hline on & No. of Case & Main Symptom & & No & $\mathrm{C}$ & \\
\hline Loc & & Il size & & & & \\
\hline se & .. & & & $\cdots$ & : & \\
\hline & .. & mary fistula & & & & \\
\hline $\begin{array}{l}\text { scharge } . \\
\text { traction } .\end{array}$ & $\begin{array}{ll}. & 1 \\
. & 1\end{array}$ & Axillary lymphad & p & & & \\
\hline
\end{tabular}

13 patients had no symptoms but requested examination.

Hammersmith Hospital and Royal Postgraduate Medical School, London W.12

B. E. NATHAN, M.B., B.CH., F.F.R., Senior Registrar, Department of Diagnostic Radiology (At present Consultant Radiologist, Edgware General Hospital, Edgware, Middlesex)

J. IAN BURN, F.R.C.S., Consultant Surgeon and Head of the Breast Unit

D. P. MACERLEAN, M.B., B.CH., D.M.R.D., Registrar, Department of Diagnostic Radiology the menstrual cycle or whether they were taking any form of contraceptive or other hormonal medication.

In general, patients attending the clinic in whom the clinical diagnosis of cancer was unequivocal did not have mammary thermography, a fact which accounts for the somewhat low incidence of malignant lesions in the series. Subsequent histological diagnosis was obtained by drill biopsy (Burn, 1971) or by examination of excised tissue when operation was indicated. All patients have been followed up for at least nine months.

The first 97 patients in the series were examined with a Bofors I-R thermographic camera and these have already been reported (Nathan et al., 1970). The remaining 262 patients were examined with an E.M.I. Thermoscan Unit. Each patient was seated facing the camera which was about 3 feet $(91 \mathrm{~cm})$ away. The patients were unclothed to the waist with the arms abducted away from the chest wall. The breasts of patients scanned by the Bofors camera were cooled by the application of alcohol swabs for 5-10 minutes before the examination. This method was not adopted when we used the E.M.I. thermal camera, preliminary cooling being achieved by the patients sitting unclothed to the waist for 10 minutes in a cool atmosphere before thermoscanning began. Every patient had both breasts scanned simultaneously and the images were recorded on Polaroid film.

In the first group of 97 patients the thermograms were originally interpreted as being normal, suspicious, or abnormal. For the purpose of the present analysis, however, these thermograms were re-examined and reported as normal or abnormal in accord with the method adopted in the reporting on all the subsequent material. All the thermograms were read by two experienced observers, both radiologists (B.E.N. and D.P.M.), without knowledge of the clinical findings. A thermogram was regarded as normal if the heat pattern from both breasts was symmetrical, with no localized area of increased heat. A thermogram was reported abnormal when there was a well-defined localized "hot-spot" or clear inequality between the two breasts, although absolute temperature differences were not recorded. As stated previously, thermography was carried out irrespective of the stage of the menstrual cycle and no attempt was made therefore to correlate the heat pattern with cyclical changes in the breasts.

\section{Results}

Of the 359 patients in the series 128 had subsequent histological confirmation of a pathological lesion in the breast and 15 underwent excision biopsy but no abnormality was found. Excision biopsy was not done in the remaining 216 patients who had simple mastodynia, diffuse fibroadenosis, solitary cyst, or periodic segmental nodularity. Biopsy was never undertaken in the presence of abnormal thermography unless there was supporting clinical or mammographic evidence to justify this.

Abnormal Thermograms. - Of 195 patients who had abnormal thermograms 27 had cancer of the breast and 53 had histologically confirmed benign lesions. In the remaining 115 no localized pathological lesion was confirmed although in some of these women symptoms such as diffuse or segmental mastodynia persisted. Seven of these 115 women had excision biopsies of painful nodular segments of breast tissue and no abnormality was found. There was no indication for biopsy in the remaining patients. The abnormal thermograms in these 115 patients $(59 \%)$ must be regarded as false positives.

Normal Thermograms. - Normal thermograms were reported in 164 patients. Cancer of the breast was subsequently diag- 
nosed in 7 and 41 had histologically confirmed benign lesions. In the remaining 116,8 of whom underwent biopsy, no localized pathological lesion was present. The incidence of false-negative thermograms was thus $29 \%$ if all the $\mathbf{4 8}$ patients with confirmed pathological lesion are included in this definition.

Thermography in Patients with Cancer.-Considering the data in another way, of the 34 women with confirmed mammary cancer 27 had abnormal thermograms (Table II)-26 had carcinomas and one had a sarcoma. Seven patients $(21 \%)$ with

TABLE II-Thermographic Findings in 128 Patients with Histologicallyverified Mammary Disease

\begin{tabular}{|c|c|c|c|c|}
\hline & & $\begin{array}{c}\text { Abnormal } \\
\text { Thermogram }\end{array}$ & $\begin{array}{c}\text { Normal } \\
\text { Thermogram }\end{array}$ & Total \\
\hline $\begin{array}{cc}\text { Malignant } & \ldots \\
\text { Carcinoma } & \cdots \\
\text { Sarcoma } & \cdots \\
\text { Benign ... } \\
\text { Fibrocystic disease } \\
\text { Chronic inflammato } \\
\text { Benign tumours } \\
\text { Miscellaneous }\end{array}$ & 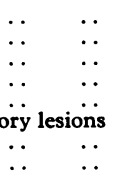 & $\begin{array}{r}27 \\
26 \\
1 \\
53 \\
40 \\
8 \\
3 \\
2\end{array}$ & $\begin{array}{r}7 \\
7 \\
0 \\
\mathbf{4} \\
29 \\
29 \\
4 \\
6 \\
6 \\
2\end{array}$ & $\begin{array}{r}34 \\
33 \\
1 \\
94 \\
69 \\
12 \\
9 \\
4\end{array}$ \\
\hline
\end{tabular}

cancer had reported normal thermograms. This figure is disturbing in view of the fact that these were all cancers which had reached the stage of causing local symptoms.

Thermography in Patients with Benign Lesions.-No fewer than $53(56 \%)$ of the 94 patients with histologically confirmed localized benign lesions had abnormal mammary thermograms. As shown in Table II, no particular condition accounted for this finding, mammary thermography being of no help in differentiating between the various types of benign lesions. The most common benign condition confirmed histologically was localized fibrocystic disease. Abnormal and normal thermograms were distributed fairly evenly among these 69 patients with fibrocystic disease.

Thermography in Patients with No Abnormality.-The final analysis of data concerns the results of mammary thermography in the women with no confirmed localized pathological lesion. There were 231 such women, of whom only 15 were considered to require a biopsy. No fewer than $115(50 \%)$ of these patients had abnormal thermograms, 51 of whom also had mammography with no indication for biopsy. Subsequent follow-up of at least nine months has given no reason to suppose that any of these patients has an as yet undiagnosed malignant or localized benign lesion.

\section{Discussion}

Our experience of mammary thermography in women with symptomatic disorders of their breasts leads us to conclude that the technique is of no help in differential diagnosis. The features of abnormality in thermography, unlike those on mammography, are non-specific. It is clear that benign lesions of all types can result in an abnormal heat pattern. The localized "hot-spot" on thermography can be equally representative of a segment of fibroadenosis as of an infiltrating carcinoma. A benign lesion is less likely than a cancer to cause an abnormality on the thermogram but this does not help to decide in the individual patient. Equally, the presence of a normal thermogram does not exchude the possibility of malignancy.

Even with more sophisticated equipment, quantifying techniques, and greater experience in interpretation, it is difficult to visualize that mammary thermography will ever be of real help in the differential diagnosis of lumps and other symptomatic disorders of the breasts. Certainly thermography will never obviate the need for biopsy, which is the major consideration for the surgeon.

What then of the potential of mammary thermography in the screening of women for early asymptomatic cancer of the breast? Enthusiasm for "well-women" clinics is mounting and a number are operational in the United Kingdom, the prime objective being the early diagnosis of mammary cancer. Public demand for this type of service undoubtedly will increase. Is it reasonable to support the concept of thermographic examination being an essential part of such a service?

Although reports have been published of the occasional diagnosis of early mammary cancer by thermography alone (Aarts, 1969; Gershon-Cohen and Hermel, 1969; GershonCohen et al., 1970), our experience leads us to doubt its value as a screening procedure. In our series of patients with symptoms a disturbing number of women with neither clinical nor mammographic evidence of abnormality had abnormal thermograms. The thermographic abnormality in these women was indistinguishable from that seen in patients with organic disease of the breasts, both benign and malignant. The situation is further complicated by the observation of Watmough and Oliver (1969) that, even when there is an organic lesion, the recorded "hotspot" on the thermogram does not necessarily coincide with the site of the lesion. In general, therefore, the decision to carry out an excision biopsy of a breast solely as a result of an apparently abnormal thermogram would be hard to justify.

Should thermography find a permanent role in mammary screening programmes, it would be unwise to use it as a preliminary method of selection for subsequent clinical examination and mammography. In our series many women with palpable abnormalities, even cancers, had normal thermograms, and presumably this would apply also to asymptomatic disorders. We agree with Furnival et al. (1970) that isolated thermography should have no place in mammary screening programmes and that such a policy would be dangerous.

The undoubted attraction of mammary thermography is its complete safety and the fact that the examination can be repeated at regular intervals without hazard to the patient. Once a baseline thermographic pattern has been established for any individual woman then any subsequent unexplained variation could justifiably be regarded as representing a fresh development and possibly disease. Some previous reports have exaggerated the usefulness of the technique, however, and the topic has unfortunately become somewhat emotive. Simmons (1971) accused clinicians of "indifference or outright antipathy" for failing to make full use of thermography, a viewpoint which showed a lack of understanding of the clinical problem.

There is need for continued careful evaluation of thermography as a diagnostic method, but it must be recognized that for the present its practical usefulness is extremely limited. Thorough examination of the breasts by an experienced clinician remains the most reliable method of detecting and localizing abnormalities within the breasts. Mammary thermography in its present form is an interesting ancillary investigation but no more than that.

We are indebted to Guest Electronics Ltd. for the loan of the Bofors I-R camera and to E.M.I. Electronics Ltd. for the loan of the E.M.I. Thermoscan Unit. We are grateful to Dr. F. H. Doyle for his continued help and support in this study.

\section{References}

Aarts, N. J. M. (1969). Bibliotheca Radiologica, 5, 40.

Burn, J. I. (1971). Proceedings of the Royal Society of Medicine, 64, 254.

Draper, J. W., and Jones, C. H. (1969). British fournal of Radiology, 42, 401 Furnival, I. G., et al. (1970). British Medical fournal, 4, 461

Gershon-Cohen, J., Haberman-Brueschke, J., and Breuschke, E. (1965) Radiologic Clinics of North America, 3, 403.

Gershon-Cohen, J., and Hermel, M. B. (1969). Cancer (Philadelphia) 24, 1226.

Gershon-Cohen, J., Hermel, M. B., and Murdock, M. G. (1970). Cancer (Philadelphia), 26, 1153.

Lloyd Williams, K., Lloyd Williams, F. J., and Handley, R. S. (1961).

Lancet, 2, 1378.
Nathan, B. E., Galasko, C. S. B., and Pallett, J. E. (1970). British fournal of Surgery, 57,518

Simmons, J. (1971). New Scientist and Science fournal, 51, 707.

Watmough, D. J., and Oliver, R. (1969). British fournal of Radiology, 42, 411. 